\title{
LIDERANÇA EM ENFERMAGEM: ABORDAGEM ECOSSISTÊMICA COM IMPACTO NO CUIDADO
}

Liliane Alves Pereira ${ }^{1}$, Aline Marcelino Ramos¹, Claudia Denise Schallenberger¹, Martha Cezar Vazl, Edison Luiz Devos Barlem¹

Objetivo: Refletir sobre o exercício da liderança em enfermagem a luz dos princípios da Sistêmica de Frontier, como razão das ações dos profissionais de enfermagem, o cuidado, este perpassa todas as esferas do ser e fazer-se enfermeiro. Desenvolvimento: a partir do referencial sistêmico de Frontier, de teóricos da liderança em enfermagem, que primam pelo cuidado nas relações pessoais, interpessoais e interprofissionais considerando não ser possível liderar sozinho, como também não é possível cuidar sozinho, que a liderança e o cuidado precisam estar entrelaçados numa teia de relações que fará das atividades ações exitosas que poderão emergir novas ações capazes de contagiar o ambiente que o cerca, cientes de que o todo interfere nas partes e que as partes só têm sentido se estiver emaranhada no todo.

Descritores: Liderança; Enfermagem; Ecossistema.

\section{LEADERSHIP IN NURSING: ECOSYSTEM APPROACH WITH THE IMPACT CARE}

Aim: To reflect on the nursing leadership exercise in the light of the principles of the Frontier Systemic, as a reason for the actions of nursing professionals, care, this permeates all spheres of being and become a nurse. Development: from Frontier's systemic referential, nursing leadership theorists, who care for personal, interpersonal and interprofessional relationships considering that it is not possible to lead alone, nor can care alone, that leadership and care need be intertwined in a web of relationships that will make activities successful actions that may emerge new actions capable of infecting the surrounding environment, aware that the whole interferes in the parts and that the parts only make sense if it is entangled in the whole.

Descriptors: leandership; nursing; ecosystem

\section{LIDERAZGO EN LA ENFERMERÍA: ENFOQUE DE ECOSISTEMA CON PRECAUCIÓN EN IMPACTO EN LAATENCIÓN}

Objetivo: reflexionar sobre el ejercicio del liderazgo en enfermería la luz de los principios de la Sistémica de Frontier, como razón de las acciones de los profesionales de enfermería, el cuidado, éste atravesa todas las esferas del ser y hacerse enfermero. Desarrollo: a partir del referencial sistémico de Frontier, de teóricos del liderazgo en enfermería, que priman por el cuidado en las relaciones personales, interpersonales e interprofesionales considerando no ser posible liderar solo, como tampoco es posible cuidar solo, que el liderazgo y el cuidado necesitan estar entrelazados en una red de relaciones que hará de las actividades acciones exitosas que podrán emerger nuevas acciones capaces de contagiar el ambiente que lo rodea, conscientes de que el todo interfiere en las partes y que las partes sólo tienen sentido si están enmarañadas en el todo.

Descriptores: Liderazgo; enfermería; ecosistema 


\section{INTRODUÇÃO}

A abordagem ecossistêmica identifica e avalia a importância dos diferentes determinantes da saúde de um ecossistema e seus convivas. Estes determinantes podem então ser usados para desenvolver uma resposta social adequada e medir a eficácia de intervenções ${ }^{(1,2)}$.

O (re) pensar as práticas cotidianas na relação com o ecossistema, abarca as práticas pessoais e sociais, e as ações do ser humano refletem no todo. Vale recordar que, as omissões não são ausências de decisões, mas são as capacidades de decidir por não decidir. Nesta definição encontra-se a singularidade do ser humano ${ }^{(3)}$. Esta decisão perpassa as diferentes realidades do ser humano e o faz ser quem se é nas suas ações cotidianas, o que tende a promover ações mais sólidas ou não. Aqui reside uma linha tênue entre o ser e o fazer da enfermagem na visão ecossistêmica, pois o termo ecossistema compete à dinâmica, interação e relação natural dos organismos e seu ambiente ${ }^{(4,5)}$. As atividades essenciais de enfermagem competem à dinâmica dos relacionamentos de todos interagindo dentro dos ambientes, pois cada um manifesta sua necessidade e o profissional tende a estabelecer vínculos equânimes ${ }^{(3)}$. A equidade em saúde está pautada no olhar diferenciado em que conceito de cuidado esta permeado pelas experiências pessoais e culturais do que é cuidar e do que é ser cuidado, pois as mudanças sociais e culturais influenciam na expressão do cuidado e na equidade em saúde,

reconhecendo o ambiente, deixando emergir as ações necessárias aos cuidados da saúde populacional(7). Neste enfoque a liderança em enfermagem tem a habilidade, competência e dever de ser o elo entre o ambiente e os pares responsáveis por ações de cuidado desenvolvendo a sensibilidade frente as situações de vulnerabilidade dos pacientes e do ambiente promovendo um cuidado integrado ${ }^{(8)}$.

Ao abordar os três princípios da sistêmica considera que o princípio da dependência interativa é o elemento em que nada se faz ou se constrói sozinho, todos os elementos só o são na relação(9). Todavia, esta própria relação ganha sentido quando ocorre um princípio de emergência, de uma entidade global nova em relação aos elementos e exerce interatividade com o meio; este segundo princípio dá sentido ao primeiro, pois não basta possuir uma inter-relação, ela deve transformar os pares e o meio e se deixar transformar por ele. $O$ terceiro princípio versa que existe um princípio de efeito de retorno do todo sobre as partes, pois não é apenas o novo emergente que influencia, mas ambos interagem e criam auto-organizações capazes de fortalecer as relações entre si e com o ambiente interno e externo. Assim este artigo tem como objetivo refletir sobre a lide- rança em enfermagem e seus impactos no cuidado a partir dos princípios da Sistêmica de Frontier.

Trata-se de um estudo de reflexão da disciplina Trabalho da Enfermagem/Saúde no Contexto Socio-ambiental, no Doutorado do Programa de Pós-Graduação em Enfermagem, da Universidade Federal do Rio Grande.

A liderança é uma habilidade construida ao longo do processo de vida, e solidifica-se a partir das experiências relacionais que o ser humano faz consigo mesmo, com pessoas e o ambiente. Dessa forma, a liderança é um importante componente para a criação de um clima favorável, harmonioso e menos conflituoso para os profissionais de saúde e para o paciente ${ }^{(10)}$.

A liderança exige inter-relação entre todos os elementos existentes na cultura organizacional, pessoal, coletiva e institucional. Ao líder cabe o papel de criar, manter ou readequar modelos com múltiplos protagonistas, inclusivo a si para que o objetivo comum seja alcançado como um processo construtivo e jamais acabado (11).

A Liderança em enfermagem só tem sentido se for desenvolvida com o objetivo de promover o bem-estar integral e social das pessoas e da realidade. Assim, pressupõe uma liderança pautada no simbólico ${ }^{(12)}$.

A partir do exposto os princípios da sistêmica traz em si um olhar ecossistêmico para a liderança fundamentada nas (inter) relações, construída para que o cuidado em enfermagem seja desenvolvido à luz do ser e fazer integrador.

\section{PRINCÍPIO DE DEPENDÊNCIA INTERATIVA}

A liderança em enfermagem se entrelaça e se constrói mediante as relações de dependência de uns com os outros e destes com o meio, assim as relações interpessoais são atributos no processo de construção do enfermeiro líder. A capacidade do enfermeiro em interagir com diferentes setores do ambiente, construindo uma rede de inter-relações favoráveis, reflete a maturidade do enfermeiro e torna-se um espelho a ser seguido ${ }^{(13)}$. Há corresponsabilidade nas ações de cuidado de modo que todos os envolvidos sintamse protagonistas de suas ações.

Se ocorrer um isolamento destes elementos da liderança as relações ficam falhas e torna-se impossivel manter o meio. Quando, este isolamento ocorre o cuidado não é realizado de forma holística, as ações no ambiente apresentam-se fragmentadas e as relações frágeis. $\mathrm{O}$ isolamento acarreta modificação do elemento e repercuti na liderança, no processo e ações de cuidado. Com este olhar não se pode agir sobre um elemento da liderança (líder, equipe e ambiente) sem que esta ação repercuta sobre os outros ${ }^{(9)}$. Dada a sua natureza integrada e holística, esta abordagem integra o conhecimento local para a realização de pesqui- 
sas e intervenções resultantes da ação. Reconhece a comunicação como um fator determinante no processo de cuidar e de liderar ${ }^{(2,14)}$.

As relações interpessoais, interprofissionais e interdisciplinares tem uma ênfase neste princípio, pois a interdependência mencionada anteriormente considera que um determinado efeito sobre uma das áreas de atuação repercute em outras áreas far-se-á um efeito cascata a médio prazo podendo interagir no elemento de partida como um efeito retorno ${ }^{(10)}$.

Esta habilidade de percepção que o elemento inicial pode contornar a cadeia de interatividade e influenciar o elemento de partida faz com que o líder reconheça a habilidade do outro, a tensão de ambos e a busca de um equilíbrio pessoal e harmonioso consigo mesmo e com a realidade que o cerca, ele entende que não é o centro das atenções e muito menos das ações ${ }^{(13)}$. Acreditar neste potencial e perceber que a diferença é a mola propulsora para o cuidado e pode ajuda-lo a firmar sua liderança e reconhecer a equidade, singularidade e individualidade como parte desta fase.

Aqui reside uma linha tênue entre o ser e o fazer da enfermagem na visão ecossistêmica, pois o termo ecossistema compete à dinâmica, interação e relação natural dos organismos e seu ambiente. Essa dinamicidade advém das diferenças, das singularidades culturais e sociais em que o ser humano estabelece suas relações ${ }^{(15)}$.

\section{PRINCÍPIO DA EMERGÊNCIA DE UMA ENTIDADE GLOBAL NOVA EM RELAÇÃO AOS ELEMENTOS E INTERATIVIDADE COM O SEU AMBIENTE}

A tensão mencionada faz parte da busca por uma nova entidade global capaz de integrar as relações nas suas diferentes nuances da liderança. Esta visão integradora do enfermeiro líder faz com que este se atente para o desgaste que pode ocorrer quando um dos elementos novos emerge para uma mudança ou até uma reorganização em virtude da necessidade de saber priorizar, o que precisa ser o objetivo comum da equipe.

Esta diversidade vale para a gestão, pois dará ao cenário uma tonalidade de equilibrio e sustentabilidade diante das adversidades que o cuidado pode se manifestar, será esta diversidade quem tornará o sistema mais forte e mais integrador. A busca cotidiana de equilibrio e harmonia levará o líder e o ambiente a reconhecer o que se é (certezas e incertezas, fragilidades e potencialidades) estimulando a sensibilidade moral ${ }^{(8)}$

Estes elementos pessoais emergentes integrados aos elementos já existente fortalece o cuidado em enfermagem e baliza as ações e o objetivo comum vai ganhando contornos à luz do novo emergente, as ações de cuidado são resignificadas e fortalecidas. Portanto, o cuidado não foi mudado, ele foi redimensionado e recebeu novo sentido a partir da interatividade.

Ao trabalhar com as tendências e considerar o que significaria para alterar cenários prováveis através de planejamento intencional, é possivel basear-se no futuro preterido, as escolhas e compromissos que são feitos neste momento, e decisões que forem tomadas agora ${ }^{(13)}$. Este é o sentido do novo emergente, que dará sustentabilidade ao futuro, terá sua influência no agora, e envolverá cada profissional neste processo de mudança.

É importante gerir o sistema (as relações) atentos para a não dominação, capaz de mensurar necessidade do ecossistema (inter-relacionar). A busca pelo equilibrio deste novo emergente requer o desenvolvimento e a interação deste com a realidade, com o ambiente e com os pares no cuidado. Ou seja, a liderança em enfermagem vislumbra nas relações, novos caminhos necessários para estabelecer processos de hierarquização onde os elementos emergentes surgem como um fio condutor auto-organizado ${ }^{(9,16)}$.

Contudo, os novos elementos não são partes que emergiram para somar as primeiras, mas surgem para dar sentido, reorganizar ou auto-organizar o que existia, o conjunto é mais do que a soma das partes, podendo ser multifacetado para o estudo, mas jamais para uma visão intervencionista, pois as relações produzem em si mesmas suas próprias interações, significando a si e aos que os cercam (17-18)

Desta forma, as relações se fazem construídas e reconstruídas em toda parte e cotidianamente, assim como o é a liderança, para que uma e outra se processem de forma coerente e eficaz é importante conhecer suas inter-relações. A liderança se complementa ao exercício do poder para constituírem a seiva que alimenta as ações e relações dos enfermeiros com as diferentes equipes, porque se entende que os sujeitos são participantes ativos no processo de cuidar e exercem o poder como tal(3).

A liderança pode potencializar a ( $\mathrm{re}$ ) construção de subjetividades nas equipes enfatizando autonomia, identidade e relações sociais. Esta permite que o enfermeiro ultrapasse as dimensões do imobilismo frente aos estigmas sociais presentes no cotidiano do fazer-se enfermeiro, ao enfrentar as subjetividades e as situações emergentes ${ }^{(19)}$.

Estas inter-relações emergentes na liderança do enfermeiro são frutos da auto-organização que vive em constante oscilação com a realidade, considerando que, o enfermeiro precisa desenvolver uma empatia e um respeito com a realidade que o circunda minimizando as situações críticas.

A enfermagem exercida nesta lógica sabe das suas dores e reconhece seu papel integrador, interlocutor e ator de novos rumos, acolhe esta tensão que vem inebriada no 
novo e estabelece confiança, compreensão e autonomia para que se tenha sempre um lugar fecundo para o novo que (re) nasce destas relações que se constroem, desconstroem e reconstroem constantemente.

\section{PRINCÍPIO DE UM EFEITO DE RETORNO}

\section{DO TODO SOBRE AS PARTES}

Este princípio tem sentido quando esta interligado ao anterior, pois de outro modo seu enunciado estaria apenas replicando o que disse o primeiro, sua razão esta no conjunto que age sobre as partes afirmando que o elemento não demonstra mesmo comportamento, mesma dinâmica, mesma evolução se estiver isolado ( o que não é possivel), se ele estiver integrado num sistema os seus desempenhos dependem do sistema de acolhimento(9).

Assim é impossivel não se modificar diante das relações, não se consegui sair de um espaço de diálogo e comunicação da mesma forma que entrou. É mister perceber que o processo de liderança só terá sentido se todos os envolvidos reconhecerem seu papel nos cenário e em si mesmo. $O$ exercício da liderança precisa perpassar três esferas distintas: o conhecimento de si, o objetivo comum e a relação com o outro.

O sentimento de pertencimento torna o ser humano um ser com a natureza, capaz de criar e recriar, com conexão física e sentimental ele sabe que está inter-relação constrói a dinâmica organizacional capaz de definir as atribuições de cada indivíduo no ambiente ${ }^{(20)}$, isto é poder. Este poder só poderá ser fidedigno se cada um se reconhecer neste ambiente tão diverso, tão inconstante e tão acolhedor.

Uma perspectiva ecológica na sociedade será criada por meio de um equilíbrio ecológico, enfocando os ambientes imediatos e apreciando a relevância do meio onde a ação do principiante faz o contorno e afeta a ação inicial, resulta no equilibrio sustentável ${ }^{(21)}$. Assim, o cuidado que é dispensado não fica sob a proteção dele mesmo, mas interage.

Nesta perspectiva de equilibrio a liderança é reconhecida como autoridade instituida e deixam-se influenciar por ela, os profissionais com papeis distintos, buscam no cuidado o objetivo comum e no ambiente o sentimento de pertença, pois a comunicação e o diálogo balizam as ações. As funções, papéis e objetivos tornam-se cada vez mais influenciados pelo efeito de retorno que o todo exerce sobre as partes, reconhecendo o valor sistêmico que é o cuidado condiciona.

O enfermeiro líder e a organização fomentam nos colaboradores a busca da autonomia e comprometimento para o desenvolvimento das funções. Desta forma, faz-se necessário o reconhecimento das ações em todos os níveis do desenvolvimento do cuidar, através de discussões de aspectos específicos da organização para que todos sai- bam decidir em diferentes espaços e a partir de suas competências, atribuições e responsabilidades.

Portanto, retorna-se ao princípio de efeito em que o todo influencia as partes e estas influências tem a capacidade de atingir e interagir entre si. Este olhar integrador faz com que a liderança em enfermagem tenha seu sentido se estiver conectado com o cuidado e este for capaz de alcançar outras realidades preponderantes do ambiente de forma contagiante e exitosa.

Partindo desta premissa, é possivel afirmar que as relações interpessoais na liderança em enfermagem traz em si mesmas o potencial transformador de intervir positivamente no cuidado, pois ao mesmo tempo em que o novo emergente (processo, comunicações, ações) vem agregar o cuidado como um novo elemento ele, por si só, transforma a liderança e transforma a si mesmo no ato de sua efetivação.

Naturalmente o ser humano tem o hábito de dividir e simplificar para compreender ${ }^{(9)}$. Todavia, esta simplificação, isolamento ou fragmentação desnatura o sistema. Assim, ao separar a tríade relação, liderança em enfermagem e cuidado, para compreendê-los corre-se o risco de não dar a estes o sentido que eles têm, pois, seu sentido só é completo se for visto de forma integrada e integradora. Existe um sistema de influenciação mútua no conceito de liderança, onde, a liderança é influenciada pelo meio e o meio a influencia, numa relação de mutualidade, intermediada pela complexidade das relações. Esta complexidade necessita de uma organização bem estruturada à luz da variabilidade que a constitui e cientes dos papéis e das funções que cada um exerce no sistema ${ }^{(18)}$.

O enfermeiro lider conhecendo a complexidade do ambiente de trabalho, necessita de uma variedade e diversidade de inter-relações com base nas regras organizacionais em que pese o fato de que se possa coordenar as partes pela sobrevivência do todo, ou seja, promover uma liderança que possa subsidiar o cuidado com ênfase nas relações saudáveis e sustentáveis.

\section{CONSIDERAÇÕES FINAIS}

A liderança como construção pessoal requer do enfermeiro uma capacidade de interação e interrelação com a equipe de trabalho multidisciplinar. As relações tendem a emergir novas formas de cuidado como intuito de aperfeiçoar, balizar e direcionar ações e processos de forma autoorganizada e até renovadora. Estas relações podem ajudar os enfermeiros a reconhecerem o potencial de cada membro da equipe e sua capacidade de ser e fazer-se profissional numa busca constante de aperfeiçoamento. Assim o novo que emergiu, para aprimorar o cuidado já existen- 
te, tende a influenciar as ações primeiras e promover uma harmonia e um equilibrio nas (inter) relações permanecendo um constante aperfeiçoamento de si, das relações e do cuidado. Portanto, conclui que diante dos princípios da sistêmica de Frontier é possível que o enfermeiro líder deixe nascer o novo que o ajuda a dar sentido ao que já está sendo feito e motive a equipe a perceber que a construção é conjunta e sempre renovável.

\section{REFERÊNCIAS}

1. Guerra G, Borde E, Salgado de Snyder VN. Measuring health inequities in low and middle income countries for the development of observatories on inequities and social determinants of health. International Journal Equity Health 2016; 15(9).

2. Forget G, Lebel J. An Ecosystem Approach to Human Health. International Journal of Occupational and Environmental Health. Suplemento, 2001; 7(2).

3. Rangel, RF, Backes DS, Ilha S, Siqueira HCH, Martins FDP, Zamberlan C. Cuidado integral: significados para docentes e discentes de enfermagem. Rev. Rene. 2017; 18(1): 43-50.

4. Piexak DR, Backes DS, Backes MTS, Santos SSC, Gautério DP. Barlem JGT. Percepção de docentes de enfermagem acerca do ambiente no cuidado ao ser humano. Revista Enfermagem UERJ. 2014; 22(4):489-93.

5. Laustsen G. Environment, Ecosystems, and, Ecological Behaviordialogue toward developing nursing ecological theory. Advances in nursing Science. 2006; 29 (1): 43-54.

6. Berssaneti FT, Saut AM, Barakat MF, Calarge FA. Is there any link between accreditation programs and the models of organizational excellence? Rev Esc Enferm USP. 2016; 50(4):648-55.

8. Baykara ZG, Demir SG, Yaman S. The effect of ethics training on students recognizing ethical violations and developing moral sensitivity. Nurs Ethics, 2015; 22,(6): 661-75.

9. Frontier S. Sistemas e ecossistemas: definições. In. Frontier. Os ecossistemas. Lisboa (PT): Instituto Piaget; 2001; 13-30.

10. Markaroff K, Storch J, Pauly B, Newton L. Searching for ethical leadership in nursing. Nursing Ethics. 2014; 21(6): 642-58.
11. Barreto MTS, Kishore A, Reis GG, Baptista LL, Medeiros CAF. Cultura organizacional liderança: uma relação possivel? Rev. Adm. 2013; 48(1): 34-52.

12. Brady-Schwartz, D.; Spencer, T.; Wilson, B.; Wood,K. Transformational Leadership: Implications for Nursing Leaders in Facilities Seeking Magnet Designation. AORN. 2011; 93(6):737-48.

13. Salanova M, Lorente M L, Chambel M J, Martinez IM. Linking transformational leadership to nurses' extra-role performance: the mediating role of self-efficacy and work engagement. Journal of Advanced Nursing. 2011; 67(10): 2256-66.

14. Kaiser JA. The relationship between leadership style and nurseto-nurse incivility: turning the lens inward. J Nurs Manag. 2016.

15. Johansson G, Andersson L, Gustafsson B, Sandahl C. Between being and doing - the nature of leadership of first-line nurse managers and registered nurses. Journal of Clinical Nursing. 2010; 19(1): 2619-28.

16. Pereira LA, Primo LS, Barlem JGT, Barlem ELD, Ramos AM,Hirsch CD. Nursing and leadership: perceptions of nurse managers from a hospital in southern Brazil. Rev. de Pesquisa: Cuidado é Fundamental Online, 2015; 7(1): 1875-82.

17. Broca P V, Ferreira MA. Equipe de enfermagem e comunicação: contribuições para o cuidado de enfermagem. Rev. bras. enferm. 2012; 65(1): 97-103.

18. Moran, E. O método 6: ética. Porto Alegre: Sulina; 2005

19. Foucault, M. Microfísica do poder. 26. ed. Rio de Janeiro: Edições Graal; 2008.

20. Anaker A. Elf M. Sustainability in nursing: a concept analysis. Scans J. Caring Sci. 2014 Mar; 1(1): 1-9. 